\title{
Mapeamento da produção científica sobre COVID-19
}

Iara Gomes Vasconcelos ${ }^{1}$

Danilo Alves do Nascimento

\section{RESUMO}

O objetivo deste estudo foi mapear a produção científica sobre COVID-19, através de uma análise bibliométrica. Os procedimentos metodológicos foram delineados por uma abordagem quantitativa, a pesquisa envolveu dados retirados do banco de dados científicos Scopus. A palavra-chave "COVID-19" foi utilizada para as buscas no referido banco de dados, dentro de um período de janeiro de 2019 a 01 de junho de 2020. Nas buscas foram identificadas 5.570 publicações relacionadas ao tema. O ano com o maior número de publicações foi o ano de 2020, com 5.560 publicações. Quanto às áreas de publicação do artigo, as que mais se destacaram foram: Medicina e Bioquímica, Genética e Biologia Molecular, com 4.161 e 594 artigos publicados, respectivamente. Entre os periódicos, o BMJ Clinical Research Ed obteve o maior número de publicações sobre o tema pesquisado. China e EUA foram os países que mais publicaram artigos e o idioma mais utilizado foi o inglês.

Palavras-chave: covid-19; sars; bibliometria.

\section{INTRODUÇÃO}

A partir de dezembro de 2019, onde um grupo de pacientes foi internado em hospitais com diagnóstico inicial de pneumonia de etiologia desconhecida, em Wuhan na China, o mundo tomava conhecimento do novo coronavírus, que foi nomeado de COVID-19 pela OMS em fevereiro de 2020 [1]. Faziam parte deste primeiro grupo de infectados pessoas que trabalhavam nos mercados atacadistas de frutos do mar e animais úmidos em Wuhan [2].

Os primeiros casos no Brasil foram registrados no final do mês de fevereiro de 2020, segundo o Ministério da saúde até a data de 23 de junho de 2020 foram registrados 1.145.906 de casos e 52.645 óbitos [3].

O termo bibliométrico é derivado da fusão do sufixo "métrica" com bibliografia, informação, ciência e biblioteca [4]. Os estudos bibliométricos são utilizados para avaliar a produtividade e a qualidade da pesquisa dos cientistas, através da medição com base no número de publicações e citações dos diversos pesquisadores [5].

Uma pesquisa bibliométrica permite identificar e descrever uma série de padrões na produção de conhecimento científico. Além disso, serve para estimar, com qualidade e quantidade, a produção de artigos científicos publicados sobre um tema específico, destacando os principais autores (pesquisadores e instituições) envolvidos nesse processo, que colaboram para o desenvolvimento da ciência [6].

A metodologia utilizada nesta pesquisa teve caráter quantitativo e descritivo, que contou inicialmente com um levantamento bibliográfico sobre COVID-19. Foram realizadas pesquisas no banco de dados de produção científica Scopus, com base em artigos publicados em periódicos indexados relacionados ao tema. O tempo utilizado nesta pesquisa compreendeu o período de 2019 e 2020.

Quanto aos critérios de busca utilizados nas bases de

${ }^{1}$ Centro Universitário UNINOVAFAPI, Teresina, Piauí, Brasil.E-mail: iaragv_91@hotmail.com

${ }^{2}$ Instituto Federal do Piauí, Departamento Gestão E Negócios, Campo Maior, Piauí, Brasil. E-mail: daniloalves@ifpi.edu.br

Como citar este artigo / How to cite this article

Vasconcelos IG, do Nascimento DA. Mapeamento da produção científica sobre COVID-19. InterAm J Med Health 2020;3:e202003044. 
acadêmica, a palavras-chave inserida no campo "title" da base de dados citada, obedecendo ao intervalo de tempo estabelecido pela pesquisa, entre 2019 e 2020. A palavrachave utilizada na busca foi: "COVID-19"

Após a coleta, os dados foram transportados para uma planilha, onde foram processados, organizados $e$ tabulados, gerando gráficos estatísticos relacionados aos indicadores bibliométricos relacionados ao tema

Gráfico 1. Número de publicaçōes por área

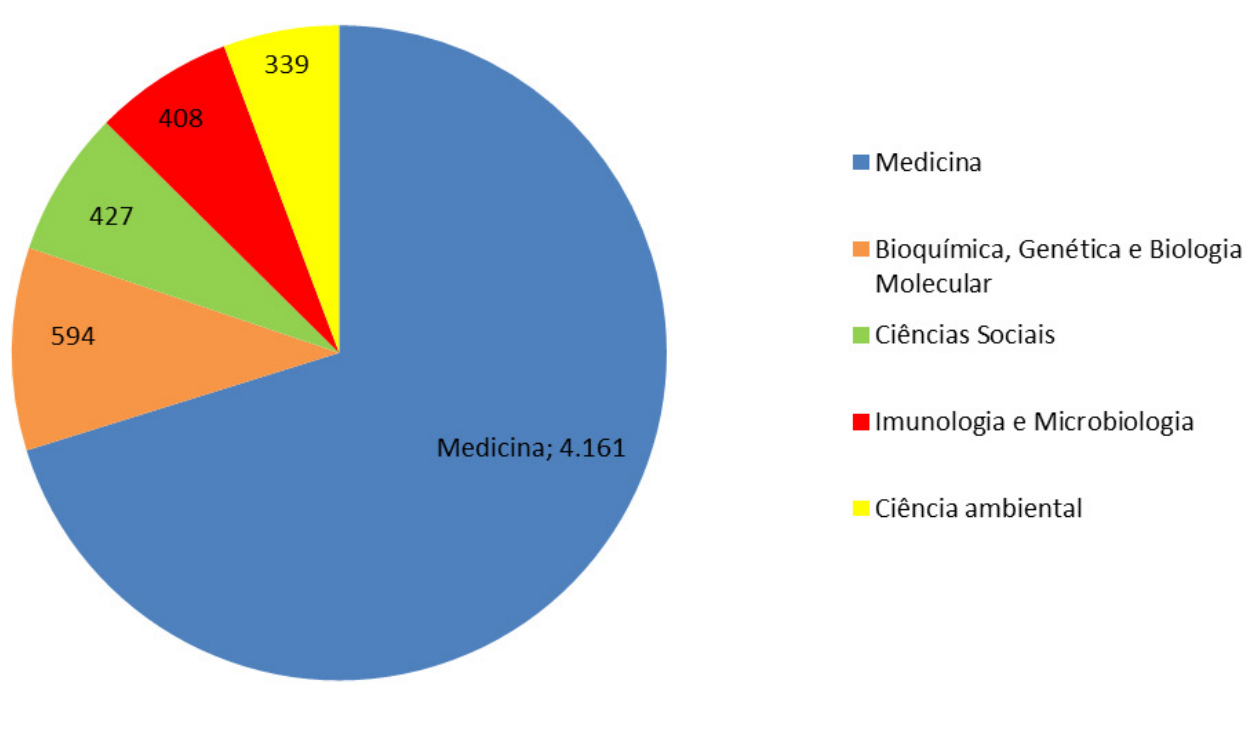

Fonte: Elaborada pelo autor (2020)

Conforme o gráfico 1 as cinco áreas que mais publicaram sobre COVID-19 foram: Medicina, Bioquímica, genética e biologia molecular) representam 85,4\% de Genética e Biologia Molecular, Ciências Sociais, todas as publicações sobre o tema no período observado. Imunologia e Microbiologia, e Ciência ambienta.

Tabela 1. Número de publicaçōes por periódicos

\begin{tabular}{lr}
\hline PERIÓDICOS & NÚMERO DE PUBLICAÇÕES \\
BMJ Clinical Research Ed & 284 \\
International Journal Of Environmental Research And Public Health & 115 \\
Science Of The Total Environment & 98 \\
International Journal Of Infectious Diseases & 83 \\
International Journal Of Advanced Science And Technology & 72 \\
\hline
\end{tabular}

Fonte: Elaborada pelo autor (2020)
Quantos aos periódicos que mais publicaram que tem a missão de promover o intercâmbio científico pesquisas sobre COVID-19, o periódico londrino que atua e publicou 115 artigos científicos sobre COVID-19. Em desde 1988 - BMJ Clinical Research Ed - publicou 284 terceiro lugar, o Science Of The Total Environment que é artigos. Seguido do International Journal Of Environmental uma revista internacional multidisciplinar de alto impacto, artigos. Seguido do International Journal Of Environmental uma revista internacional multidisciplinar de alto im na plataforma Scopus, onde apenas 10 foram publicados
Foram encontrados 5.570 artigos sobre COVID-19 no ano de 2019 e os outros 5.560 no ano de 2020.

Tabela 2. Número de publicaçōes por instituiçōes/organizaçōes

\begin{tabular}{lr}
\hline INSTITUIÇÃO/ORGANIZAÇÃO & NÚMERO DE PUBLICAÇ̃̃ES \\
Huazhong University of Science and Technology & 140 \\
Harvard Medical School & 66 \\
Fudan University & 61 \\
Università degli Studi di Milano & 56 \\
Zhongnan Hospital of Wuhan University & 52 \\
\hline
\end{tabular}

Fonte: Elaborada pelo autor (2020)

Também foi realizada uma análise quanto às Harvard (HMS - Harvard Medical School) é a faculdade de instituições e/ou organizações que mais financiaram medicina da Universidade Harvard, nos Estados Unidos, estudos sobre COVID-19. A Universidade de Ciência e financiou 66 trabalhos. Seguida da Universidade de Tecnologia de Huazhong (HUST - Huazhong University Fudan (Fudan University) é uma universidade situada em of Science and Technology) é uma universidade pública Xangai na China que financiou 61 estudos sobre o novo chinesa que financiou 140 estudos sobre o tema coronavírus, conforme tabela 2.

observado. Em segundo lugar, a Escola de Medicina

Gráfico 2. Número de publicaçōes por países

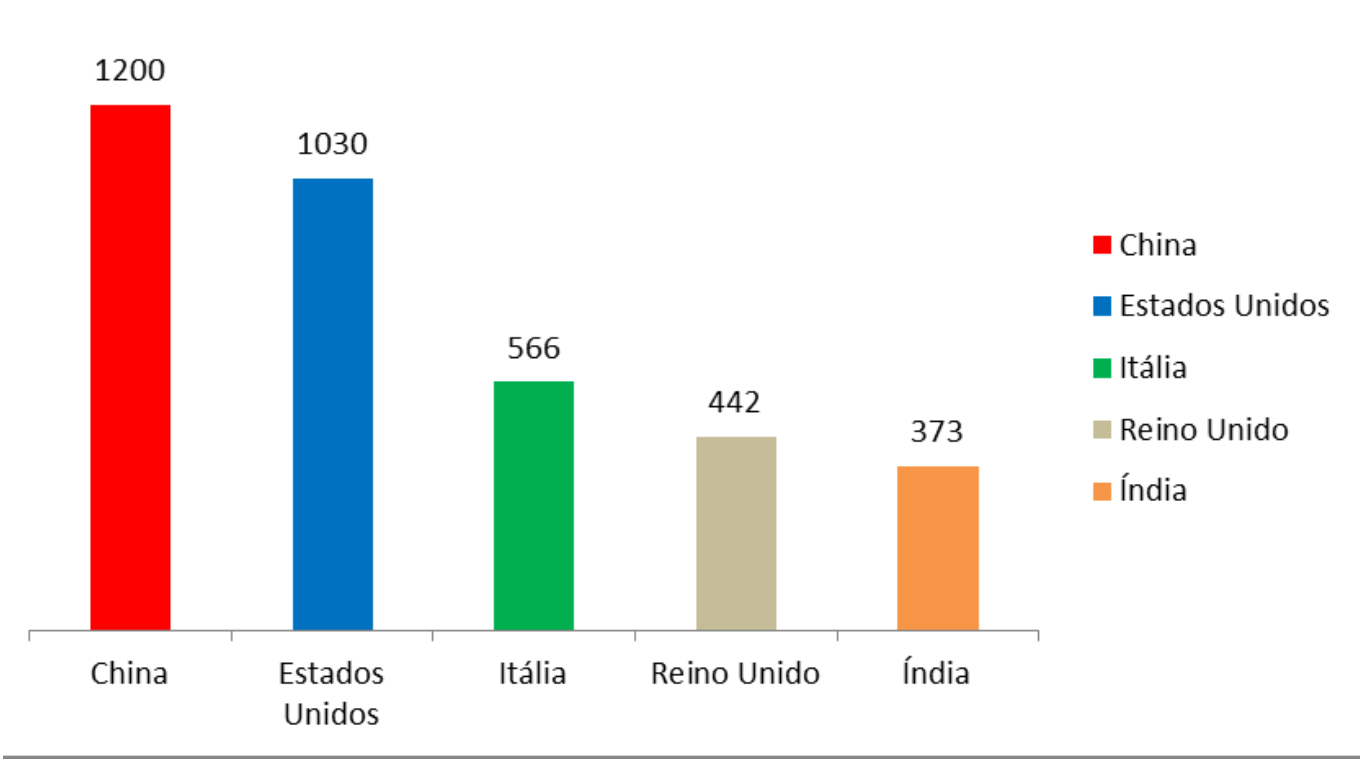

Fonte: Elaborada pelo autor (2020) 
Este trabalho analisou os países que mais publicaram ressaltar, que juntos China e EUA representam 40\% artigos científicos sobre COVID-19 na plataforma Scopus, de todas as publicações científicas sobre COVID-19, dentro do período observado. A China publicou 1200 materializando o poder das duas maiores potências artigos científicos, os EUA publicaram 1.030 estudos, em terceiro lugar a Itália figura com 566 trabalhos. Vale

Tabela 3. Número de publicaçōes por idioma

\begin{tabular}{lr} 
IDIOMA & NÚMERO DE PUBLICAÇÕES \\
\hline Inglês & 4.842 \\
\hline Chinês & 347 \\
\hline Espanhol & 103 \\
\hline Italiano & 81 \\
\hline Alemão & 64
\end{tabular}

\section{Fonte: Elaborada pelo autor (2020)}

Conforme a tabela 3 é possível perceber o domínio do idioma inglês, que é o mais utilizado nas publicações analisadas, representando $86,9 \%$ de todas as publicações sobre COVID-19. Seguidos dos idiomas chinês, espanhol, italiano e alemão. Estes números mostram que mesmos os pesquisadores chineses que publicam o maior número de artigos, preferem utilizar a língua inglesa como estratégia para obter um maior impacto na comunidade acadêmica e científica internacional.

\section{CONCLUSÕES}

Esta pesquisa buscou analisar a produção científica relacionada ao novo coronavírus no banco de dados Scopus, no corte temporal de 2019 e 2020. A mensuração da produção científica por meio da bibliometria permite avaliar o desempenho de pesquisadores, instituições, países e periódicos, através do mapeamento de artigos científicos e outras produções científicas, levando em consideração métricas quantitativas e qualitativas.

Nesta pesquisa, foram identificadas 5.570 publicações relacionadas ao tema no período analisado, o ano com maior volume de publicações sobre o assunto foi 2020 pois o novo coronavírus já foi identificado no final do ano de 2019.

Todos os artigos identificados nesta pesquisa foram analisados de acordo com os seguintes critérios: autores, áreas de conhecimento, periódicos em que foram publicados, instituições autoras de artigos, países que publicaram os artigos e idiomas que foram escritos.

Quanto às áreas de publicação dos artigos, o destaque ficou com Medicina e Bioquímica, Genética e Biologia Molecular com $85,4 \%$ das publicações. Dentre os que tiveram maior destaque em relação ao número de publicações na base de dados Scopus foram: BMJ Clinical Research Ed e o International Journal Of Environmental Research And Public Health.

A língua inglesa como sendo a mais utilizada pelos pesquisadores e o domínio da China e dos EUA como os países com maior número de produção científica também

Espera-se, por meio deste estudo, ter contribuído para a evolução do tema pesquisado, e que os resultados desta pesquisa possam beneficiar pesquisadores e estudiosos da área. Para trabalhos futuros, este estudo propõe o uso de outras bases de dados de dados de pesquisas científicas e o uso de novas palavras-chave relacionadas ao tema COVID-19.

\section{REFERÊNCIAS}

1. Rothan HA, Byrareddy SN. The epidemiology and pathogenesis of coronavirus disease (COVID-19) outbreak I Autoimmun [Internet]. 2020 [citado em 5 maio 2020];109:102433. Disponível em: https:/l www.ncbi.nlm.nih.gov/pmc/articles/PMC7127067/ os periódicos identificados na pesquisa, verificou-se que foram observadas através deste trabalho.
2. Koh D. Occupational risks for COVID-19 infection.Occup Med [Internet]. 2020 [citado em 5 maio 2020];70(1):3-5. Disponível em: https:// academic.oup.com/occmed/article/70/1/3/5763894

3. Brasil. Ministério da Saúde. Coronavírus Brasil. Painel de casos de doença pelo coronavírus 2019 (COVID-19) no Brasil pelo Ministério da Saúde [Internet]. Braślia; 2020 [citado em 26 maio 2020]. Disponível em: https://covid.saude.gov.br/

4. Silva, A. P. F.; Nascimento, A. N.; Pinho, M. A. B; Falk, J. A. "Estudo bibliométrico sobre custo em organizações de construção civil: contribuições do congresso brasileiro de custos de 1996 a 2010". In: XIX Congresso Brasileiro de Custos. Anais... Bento Gonçalves/RS, 2012.

5. Vanti, N. A. P. "Da bibliometria à webometria: uma exploração conceitual dos mecanismos utilizados para medir o registro da informação e a difusão do conhecimento". Ciência da Informação, Braślia, v. 31, n. 2 p. 52-62, 2002.

6. Bastos, E.; Hein, N.; Fernandes, F. "Inserção da controladoria em artigos publicados em eventos científicos nacionais". In SimpósiodeExcelênciaem GestãoeTecnologia. Niterói/RJ,2006. 